\title{
PRIMENA ALGORITAMA ZA REPROJEKCIJU RASTERSKIH SLIKA PRILIKOM PRIKAZA VIŠESLOJNIH MAPA
}

\section{APPLICATION OF RASTER IMAGE REPROJECTION ALGORITHMS WHEN DISPLAYING MULTILAYER MAPS}

\author{
Viktor Đuka, Fakultet tehničkih nauka, Novi Sad
}

\begin{abstract}
Oblast - ELEKTROTEHNIKA I RAČUNARSTVO
Kratak sadržaj -U ovom radu vrši se upoznavanje rada sa standardnim rasterskim map servisima, integracijom ovih servisa sa klijentskim aplikacijama i prikazom tileova. Takođe, glavna stavka zadatka jeste opis geografskih podataka u različitim projekcijama, način kako reprojektovati tile-ove kao i implementacija algoritma za reprojekciju tile-ova. Analizirana su tri algoritma, od kojih su dva implementirana, a jedan je opisan kroz tekst kako se može implementirati.
\end{abstract}

Ključne reči: rasterske mape, projekcije mapa, reprojekcija tile-ova, algoritam

\begin{abstract}
This paper presents introduction with standard raster map services, integration this services with client applications and reprezentation tiles. Also, the main problem in this paper is resolving to description of geographical data in different projections, method how to reprojection tiles from one to another projection and implementation algorithm for this reprojection. The methods were analyzed for three algoritms, two of which were implemented and one was decribed throughout the text how it can be implemented.
\end{abstract}

Keywords: raster maps, map projections, reprojection tiles, algorithm

\section{UVOD}

Na samom početku važno je upoznati se sa geoprostornim podacima kao i pristupu istim preko računarskih mreža. Za korisnike ove aplikacije, to može biti zamena za razne papirne mape, karte i atlase kao i za pristup informacijama koje su nekad bile teško dostupne kao na primer satelitski snimci.

Pored opisa zadatka, biće opisani osnovni pojmovi koji su vezani za sam rad. Jedan od njih jeste geografski informacioni sistem (GIS) koji predstavlja informacioni sistem koji je dizajniran tako da radi sa podacima koji su referencirani prostornim ili geografskim koordinatama. On se može smatrati nekom vrstom baze podataka sa specifičnim atributima za skladištenje prostorno referenciranih podataka, kao i skupom operacija za rad sa tim podacima [1]. Upotreba GIS-a u aplikacijama podrazumeva prikaz, analizu i pretragu satelitskih snimaka, ulica,

\section{NAPOMENA:}

Ovaj rad proistekao je iz master rada čiji mentor je bio dr Darko Čapko, vanr. prof. puteva, raznih objekata itd. U ovom radu će biti prikazan klijentski deo aplikacije (WPF) koji će vršiti prikaz rasterskih podataka, tj, satelitskih snimaka željenih reprojektovanih tile-ova.

Serverski deo ovog zadatka jeste prikupljanje tile-ova sa eksternih servisa kojima se može pristupati. Na tim servisima se mogu čitati i prikazivati geoprostorni podaci, ali i objavljivati. To znači da je moguće da neko napravi svoje mape sa raznim podacima i zatim ih „objavi“ kao servis.

Što se tiče objavljivanja geoprostornih podataka i pristup njima, oni su regulisani sa OGC standardima. Takođe, u radu su opisani i WMS (Web Map Service) stardardi koji se koriste za rasterske podatke, tj. za georeferencirane slike. WMTS (Web Map Tile Service) standard je opisan za rasterske podatke, ali kod njih je akcenat na optimizaciji jer predviđa da se originalna georeferencirana slika deli na više delova (tile) za određene nivoe zumiranja. O ovim stvarima ima više u poglavlju 3.

Poglavlje 4 obuhvata opis projekcija mapa. One predstavljaju način na koji globus predstavljen u ravni. To zahteva transformaciju geografskih širina i dužina lokacija sa zemljine kugle u lokacije ravni.

Dalje je opisan klijentski deo aplikacije, odnosno koje sve feature-e poseduje aplikacija za reprojektovanje tile-ova. Klijentska aplikacija je WPF aplikacija koja ima razne mogućnosti poput prikaza tile-ove zadatih u nekom BBOX-u, iscrtavanje tačaka, linija, i kao glavnu karakteristiku, reprojektovanje.

Što se tiče 7. poglavlja, tamo je opisan algoritam reprojekcije korišćen u ovoj aplikaciji što predstavlja glavnu karakteristiku aplikacije. Sama aplikacija sadrži i serverski deo koji komunicira sa jedne strane sa klijentom, a sa druge strane sa eksternim servisima za dobavljanje geoprostornih podataka. U ovom poglavlju, takođe je prikazan pregled dosadašnjih rešenja, tj srodnih istraživanja, gde su navedeni srodni radovi, problemi koje su oni rešavali i po čemu se ovaj rad razlikuje u odnosu na njih.

Na kraju je opisan je zaključak gde su opisani predlozi za dalje širenje aplikacije. 


\section{SERVISI ZA MAPE}

\subsection{Tipovi servisa i osnovni standardi}

Dobavljanje geografskih podataka se veoma često obavlja putem veb servisa. Veb servisi mogu biti i nestandardni, odnosno, specifični za nekog provajdera. Jedan od takvih tipova je ArcGIS servis. Takođe, Google Maps i Yahoo! Maps predstavljaju nestandardne servise koji se uveliko koriste u mnogim sistemima (npr. android uređaji). Standarde za ove veb servise objavljuje OGC (Open Geospatial Consortium).

Jedan od standarda koji podržava podelu mape na polja je WMTS (Web Map Tile Service). Pored standardnih i nestandardnih veb servisa, postoji i mogućnost da se geografski podaci dobavljaju i sa diska, što nije uobičajna praksa. Tu se može javiti problem sa prostorom na disku, ažuriranjem mapa, sinhronizacijom, itd.

Ono što je korišćeno u ovom radu, jesu standardni servis, odnosno WMTS. Ono što je prednost kod standardnih servisa jeste što se njihovo korišćenje smatra dobrom praksom jer poseduju veliku količinu geografskih podataka uskladištenih u raznim formatima. Zato je i poželjno imati neki standardizovan interfejs za pristup istim. Takođe, još jedan razlog zbog čega je dobro imati pristup standardizovan servisu, jeste taj da ko poznaje standard po kome se pravi neki servis za mape lako može da koristi servise različitih provajdera mapa.

\subsection{Mapa podeljena na tile-ove i piramida polja}

Na slici 2.1 možemo videti sliku Kalifornije u više nivoa. Svaki od tih nivoa ima svoj kvalitet slike. Tako, na primer, nivo koji je predstavljen samo jednim poljem, ima najniži kvalitet slike. Kako se nivo povećava, odnosno zoom level, tako raste i broj polja a samim tim i kvalitet slike se poboljšava. Na nivou sa jendim poljem se ne mogu videti neki detalji, na primer ulice, dok ukoliko broj polja ode na nekih deset hiljada, videće se lepo ulice. Polja po pravilu imaju fiksnu veličinu, npr 256×256 piksela. Ovakvim načinom podele mape na polja se dobija struktura koje se zove piramida polja (tile pyramid) ili piramida slika(image pyramid) (slika 2.1).

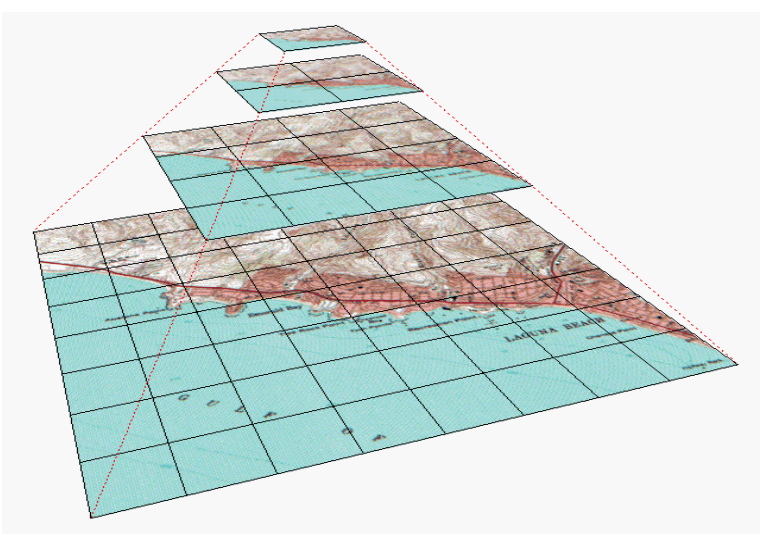

Slika 2.1 Podela slike na mape polja Kalifornije i njen piramidni prikaz

\subsection{Prednosi i nedostaci tiled mapa}

Podela mape na polja, odnosno, tile-ove, donosi neke prednosti i nedostatke. Ono što donosi prednost jeste zumiranje mape po svojim nivoima. Na taj način možemo da razdvojimo „bitne“ od „nebitnih“ stvari. Tako u nekim slučajevima, gde nam nije potreban prikaz svih detalja, već želimo da vidimo neki region samo gde se nalazi, dovoljan nam je niži zoom level. Time ne moramo sva polja da renderujemo i prikazujemo korisniku. Sa druge strane, ukoliko nam je potreban detaljan prikaz ulica, izrederovaćemo veći skup polja koji obuhvata taj region.

Primer za odsustvo podele na polja je WMS standard [3], gde je smanjena mogućnost keširanja, zato što klijent u tom slučaju zahteva sliku određene veličine, koja pokriva određeno geografsko područje, obuhvata određene slojeve, itd. Ovde je mala verovatnoća da će klijent više puta napraviti isti zahtev. Zbog toga, svaki put kad korisnik napravi zahtev, slike se generišu na serveru, što je proces koji je vremenski i računarski zahtevan i negativno utiče na skalabilnost servisa i smanjuje kvalitet servisa (QoS) za korisnike [2].

Dobavljanje polja preko mreže je popularan mehanizam preko koga klijenti za mape dobijaju podatke. Kod veb klijenata je to neophodno, a kod desktop klijenata smanjuje kompleksnost i veličinu instalacije [4].

\section{OPEN GEOSPATION CONSORTIUM (OGC) STANDARDI}

OGC je konzorcijum kompanija, nevladinih organizacija, agencija i univerziteta sa zajedničkom vizijom u kojoj svi imaju korist od geografskih informacija i servisa dostupnih preko različitih mreža, aplikacija i platformi. OGC nastoji da postigne globalni konsenzus pri razvoju standarda za interfejse i enkodiranje koji omogućavaju interoperabilnost među različitim geoprostornim bazama podataka, servisima i aplikacijama [3].

\subsection{Web Map Service (WMS)}

OGC standard definiše Web Map Service kao standard koji obezbeđuje HTTP interfejs koji služi za dobavljanje georeferenciranih slika iz jedne ili više distribuiranih geoprostornih baza podataka. U WMS zahtevu su definisani geografski slojevi i područje koje se želi prikazati. Odgovor na zahtev je jedna ili više georeferenciranih slika mapa (JPEG, PNG, itd) [3].

\subsection{Web Map Tile Service (WMTS)}

WMTS standard podrazumeva već pomenutu podelu mape na polja, i sve prednosti koje su navedene za takav pristup važe i ovde, što uključuje i ono najbitnije, a to je generisanje polja unapred, tj. serverski tile cache. Najbitniji resursi kojima se mogu pristupiti kod WMTS servisa su ServiceMetadata (metapodaci servisa) i Tile (polje). Njima se može pristupiti pomoću Get metoda [4].

\section{PROJEKCIJE MAPA}

Projekcije mapa predstavljaju način na koji globus predstavljen $u$ ravni. To zahteva transformaciju geografskih širina i dužina lokacija sa zemljine kugle u lokacije ravni. 
Transformacija projekcije mape [5] je jedno istraživačko polje projekcije mape koje proučava teorije i metode transformacije koordinate tačaka od jedne vrste projekcije do druge.

Postoje tri vrste metoda transformacije projekcije mapa [6]:

- Inverzna metoda transformacije.

- Direktni metod transformacije i kombinovani metod.

- Vrednost metoda transfomracije i vrednosnoanalitička metoda transformacije.

U ovom konkretnom radu korišćene su dve projekcije. Jedna od njih je Web Mercator projekcija (EPSG:3857) koju ću malo detaljnije opisati, a druga je manje poznata EPSG:31256 projekcija.

\section{REPROJEKCIJA TILE-OVA}

Većina softvera danas koji koriste neke map servise imaju svoju predstavu u određenoj projekciji. Kako bi došlo do validnog prikazivanja geografskih podataka, potrebno je da se nekako usklade te projekcije. Tu se javlja pojam reprojekcije.

Pojam reprojekcije ima više značenja. U ovom slučaju, pojam reprojekcije predstavlja konvertovanje koordinata iz jednog koordinatnog sistema u željeni koordinatni sistem.

Primera radi, neki klijent radi sa jednom vrstom koordinatnog sistema (npr Web Mercator), i želi da predstavi neki region u drugoj projekciji. On će poslati podatke (npr Bbox uglova koordinata) serveru koji će mu obraditi te podatke, pronaći tile-ove, konvertovati u željenu projekciju i vratiti koordinate u novoj projekciji.

U literaturi se uglavnom opisuju drugačiji sistemi i nije ista tematika ali je suština ista.

U nastavku sledi pregled najsrodnijih radova.

$\mathrm{U}$ radu Best practices for the reprojection and resampling of Sentinel-2 Multi Spectral Instrument Level 1C data [8] je opisano da na svakih 10 metara reprojektovan piksel nekog tile-a, a distance na slici 2.1 možemo primetiti distance $a, b$ i $c$ koje su kvantifikovane tamo gde se preklapaju pločice.

Rastojanja $a$ i $b$ definišu greške $\mathrm{u}$ ovom algoritmu „,najbližeg suseda“, dok $c$ kvantifikuje razliku u položaju izazvanu razmatranjem jednog, a ne drugog tile-a. Reprojektovani piksel predstavlja krstić na slici 7.8.

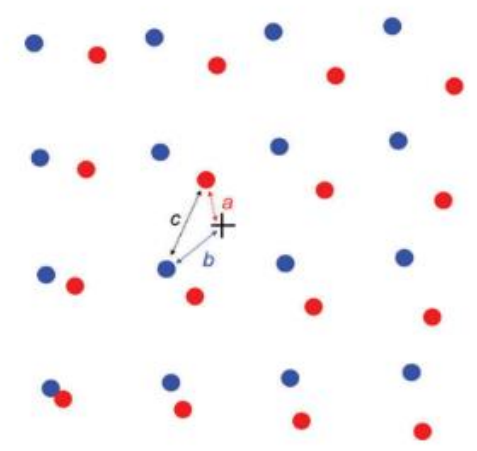

Slika 7.8 Opis algoritma najbližeg suseda iz jednog od radova [8]

\section{ALGORITAM REPROJEKCIJE}

Algoritam reprojekcije predstavlja način na koji ćemo jednu fotografiju (u našem slučaju jedan tile) u jednoj projekciji dobiti istu tu fotografiju u drugoj projekciji. Kako smo već gore naveli, zbog konverzije koordinata i njhove predstave $\mathrm{u}$ GIS-u neke koordinate jedne projekcije nisu iste u drugoj projekciji. Zato je potrebno njihovo reprojektovanje iz jednog u drugi sistem. U ovom poglavlju biće opisano nekoliko načina za ovaj poduhvat kao i načini koji su implementirani u ovom radu.

\subsection{Opis prvog algoritma reprojekcije}

Za početak, tile u EPSG:31256 je veličine 256x256 piksela. To je ukupno 65536 piksela koje sadrži ta jedna fotografija. U ovom algoritmu uzeti su u obzir apsolutno svi pikseli sa tog tile-a i svaki piksel je imao svoju poziciju na slici. Budući da je tile kvadrat, odnosno, dvodimenzijalni je tile, on u sebi ima svoje pozicije svih piksela. Pa tako za prvi piksel, pozicija je $(0,0)$, drugi $(0,1)$ itd.. Ovaj algoritam pamti svaku poziciju svih 65536 piksela. Za reprojekciju nam nisu dovoljni samo pikseli i pozicije već i koordinate tih piksela. Koordinate jednog tile-a dobijamo upotrebom WorldFile-ova [7].

$\mathrm{Na}$ osnovu WorldFile-a, imamo informaciju o gornjem levom uglu i njegovim koordinatama. Na osnovu pozicije tile-a izračunavamo i ostale uglove. Zatim na osnovu naših rubnih koordinata i na osnovu toga što znamo da po širini i po visini imamo 256 piksela, izračunavamo na koliko metara je sledeća koordinata. Taj podatak će nam biti ključan u ovom algoritmu. Zatim se iterira kroz svaku poziciju piksela i na poziciju gornjeg levog ugla se dodaje naš podatak koji smo izračunali u prethodnom koraku a to je na koliko metara je sledeća koordinata i pomnoži se sa pozicijom piksela. Ovom iteracijom dobijamo Dictionary sa 65536 podataka koji u sebi kao ključ sadrži koordinatu, a kao vrednost poziciju njegovu. Kako smo ovo izračunali prelazimo na konverziju ovih koordinata u EPSG:3857.

Za ovu konverziju koristili smo eksterni wrapper (proj_api) koji koristi eksternu biblioteku za konverziju koordinata. Svaku koordinatu smo konvertovali i smestili je u novi Dictionary koji sada u sebi sadrži koordinate u EPSG:3857 i pozicije na kojima treba da se nalazi.

Prilikom ove konverzije, odredili smo i rubne koordinate i njih sačuvali u posebne varijable kako bismo taj bbox poslali na naš server koji će nam dati tile-ove $u$ EPSG:3857. U ovom slučaju, dobili smo 6 tile-ova za gore prikazanu fotografiju.

Nakon preuzimanja tile-ova, treba pronaći gde se koja koordinata nalazi u tim tile-ovima. Na osnovu WorldFIleova pronalazimo traženi tile i iz tog tile-a izvlačimo traženi piksel koordinate koju smo poslali da se pronađe. Tako radimo za svih 65536 koordinata. Svaki piksel koji izvučemo, smestimo ga u poseban Dictionary koji u sebi ima kao ključ poziciju piksela, a kao vrednost konkretan piksel. Na osnovu ovog Dictionary-a znamo na kojoj poziciji treba da se nalazi određeni piksel i tako ga iscrtavamo na našem canvas-u.

Ovaj algoritam se ispostavio da je efikasan sa stanovišta preciznosti, ali sa stanovišta vremena obrade ove reprojekcije, nije baš efikasan. Svakim pristupom eksternoj biblioteci za konverziju fajlova izgubi se puno vremena i to je veoma zahtevan pristup. Treba 65536 puta 
pristupiti proj_api biblioteci, odnosno, 65536 puta je pozivati a to je veoma skupa operacija.

Zbog toga, implementiran je još jedan algoritam koji je brži.

\subsection{Opis drugog algoritma reprojekcije}

Drugi algoritam reprojekcije koji je implementiran u ovom radu je baziran na istom principu. Veoma je sličan prethodnom algoritmu pa će u ovom delu teksta biti opisano samo koja je razlika između njih.

Algoritam funkcioniše isto sve do onog momenta kada treba da se pristupa proj_api biblioteci. Kada se dođe do tog dela, uzima se svaki deseti piksel iz Dictionary-ja u kojem se nalaze sve koordinate iz EPSG:31256 projekcije i njihove pozicije. Pa tako kao krajnji rezultat imamo deset puta manje piksela za obradu (6554). Dalji tok ovog algoritma je isti kao što je prethodni opisen. Razlika je samo broj piksela za pristup proj_api biblioteci.

Pikseli koji nisu svaki deseti bili, njih smo računali na osnovu toga da se uzme vrednost poslednje koordinate i doda razlika dva piksela koja smo izračunali u metrima.

Tako ponovo imamo koordinate svih piksela koje treba kasnije da obradimo na isti način kao u prethodnom algoritmu samo sa 10 puta manjim pristupom proj_api-ju.

\section{ZAKLJUČAK}

U ovom radu analizirana su razni algoritmi za reprojektovanje piksela rasterskih tile-ova.

Implementirana su dva algoritma gde i jedan i drugi imaju svoje prednosti i mane.

Prvi algoritam je sa stanovišta efikasnosti veoma dobar, ali je spor. Drugi algoritam je dosta brži ali mu efikasnost nije jača strana.

U sistemima koji imaju naprednu tehnologiju i dobro razvijen informacioni sistem mogu koristiti prvi algoritam jer se ne bi osetio nedostatak brzine, a preciznost bi bila na najvišem mogućem nivou. Takođe, sistemi kojima je od bitnog značaja da reprojekcija bude veoma efikasna $i$ da se detalji ispolje na najvišem mogućem nivou, oni bi svakako koristili ovaj algoritam.

Što se tiče drugog algoritma, on bi najefikasniji bio u sistemima u kojima bi se vršilo testiranje reprojekcija kako bi se na što brži način videlo da li odgovara dobijena projekcija onom što se očekivalo.

Takođe, implementirana je i klijentska aplikacija koja koristi ove algoritme za reprojektovanje rasterskih tile-ova.

Proširenje aplikacija moguće je u više smerova.

Jedan od smerova jeste taj da kao serverski deo, moguće da bilo koja druga klijentska aplikacija koristi server kako bi se izvršila reprojekcija tile-ova. Na samom serveru ostavljena je mogućnost za proširivanje broja projekcija koje bi se obrađivale.

Takođe, aplikacija može dalje implementirati nove algoritme, i to lakim ubacivanjem novih metoda. Isto tako, klijent može da se izmeni i upotrebi za neku svrhu testiranja raznih mogućnosti pre nego što se neka ozbiljna aplikacija ne odluči za korišćenje određene projekcije.
Iako su se neki algoritmi koji su implementirani dobro pokazali, ipak treba obratiti pažnju za budući razvoj aplikacije da se opterećenje i zauzeće radne memorije svede na minimum.

\section{LITERATURA}

[1] Jeffrey Star and John Estes, "Geographic Information Systems: An Introduction" Englewood Cliffs, NJ: PrenticeHall, 1990, page 2-3

[2] Ricardo García, Juan Pablo de Castro, Elena Verdú, María Jesús Verdú and Luisa María Regueras, "Web Map Tile Services for Spatial Data Infrastructures: Management and Optimization”, Cartography - A Tool for Spatial Analysis, Dr. Carlos Bateira (Ed.), InTech, 2012, dostupno na: http://cdn.intechopen.com/pdfs/38302/InTech-

Web_map_tile_services_for_spatial_data_infrastructures_m anagement_and_optimization.pdf

[3] Open Geospatial Consortium, dostupno na: http://www.opengeospatial.org/

[4] Open Geospatial Consortium Inc., "OpenGIS Web Map Tile Service Implementation Standard”, April 2010, dostupno na: http://portal.opengeospatial.org/files/?artifact id=35326

[5] WU Z.X., HU Y.J. "The Development of Map Projection in China in the Past 30 Years (in Chinese)", Map Projection Collected Papers (in Chinese), Survey and Mapping Press, pp.1-5, Beijing, 1983

[6] WU Z.X., YANG Q.H.: "A Research on the Transformation of Map Projections in Computer-Aided Cartography (in Chinese)", Map Projection Collected Papers (in Chinese). Survey and Mapping Press, Beijing: 287--322 (1983)

[7] WorldFile, dostupno na: https://www.usna.edu/Users/oceano/pguth/md_help/html/tb me6h0z.htm

[8] David P. Roy, Jian Li, Hankui K. Zhang \& Lin Yan, „Best practices for the reprojection and resampling of Sentinel-2 Multi Spectral Instrument Level 1C data", Remote Sensing Letters, Vol. 7, No. 11, pp. 1023-1032, DOI: 10.1080/2150704X.2016.1212419, 27 Jul 2016.

Svim linkovima je pristupljeno 16.10.2020.

\section{Kratka biografija:}

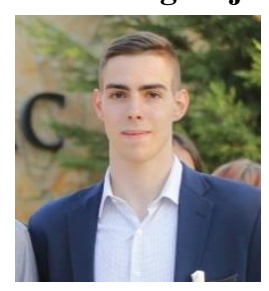

Viktor Đuka rođen je 09.02.1996. u Novom Sadu. Smer Računarstvo i automatiku na Fakultetu tehničkih nauka u Novom Sadu upisuje 2015. godine, a 2017. godine se opredeljuje za Primenjene računarske nauke i informatiku kao usmerenje. Školske 2019. Godine usmerio se na podusmerenje Softversko iznženjerstvo. Osnovne studije je završio 2019. godine i stekao zvanje diplomiranog inženjera elektrotehnike i računarstva. Master studije je upisao na istom usmerenju, takođe 2019. godine.

kontakt: viktordjuka10@gmail.com 